\title{
"Tailored" endovascular pulmonary valve and root replacement for rupture of a dilated homograft
}

\author{
Götz Christoph Müller ${ }^{1}$, Christoph Sinning ${ }^{2}$, Elvin Zengin-Sahm ${ }^{2}$, Veronika Stark ${ }^{1}$, Thomas S. Mir ${ }^{1}$, \\ Carsten Rickers ${ }^{1}$, Rainer Kozlik-Feldmann ${ }^{1}$, Tilo Kölbel ${ }^{3}$, Ulrich Schäfer ${ }^{2}$ \\ ${ }^{1}$ Department of Pediatric Cardiology, ${ }^{2}$ Department of General and Interventional Cardiology, ${ }^{3}$ German Aortic Center, Department of Vascular \\ Medicine, University Heart Center Hamburg, Hamburg, Germany \\ Correspondence to: Götz Christoph Müller, MD. Department of Pediatric Cardiology, University Heart Center Hamburg, Martinistr. 52 , 20246 \\ Hamburg, Germany. Email: go.mueller@uke.de.
}

\begin{abstract}
Current balloon expandable and self-expanding valves have limitations for the treatment of the enlarged right ventricular outflow tract. We report the first use of a tailored Zenith graft in composition with an Edwards Sapien S3 valve as an alternative to high-risk surgery for the treatment of a spontaneously ruptured homograft in an adult congenital heart disease patient.
\end{abstract}

Keywords: Pulmonary valve replacement; endovascular; bleeding; enlarged right ventricular outflow tract

Submitted Aug 01, 2018. Accepted for publication Nov 02, 2018.

doi: $10.21037 / \mathrm{cdt} .2018 .11 .06$

View this article at: http://dx.doi.org/10.21037/cdt.2018.11.06

\section{Introduction}

Twenty percent of patients with congenital heart disease have right ventricular outflow tract or pulmonary valve dysfunction (1). Pulmonary valve replacement is currently the procedure of choice for pulmonary regurgitation and hemodynamic sequelae. Surgical pulmonic valve replacement is one of the most common procedures in congenital heart disease patients. The percutaneous alternative was first performed in 2000. Bonhoeffer et al. merged a surgically available bovine jugular vein valve (Venpro/Contegra) and a Cheatham-Platinum (CP) stent to create a percutaneous system called Melody valve for stenosed conduits (2). Eighteen years later transcatheter pulmonic valve replacement is still a rapidly evolving field. Short and midterm results demonstrating good hemodynamic and clinical outcome after transcatheter valve implantation at least equivalent to surgery (3-5). Nevertheless endovascular treatment of the enlarged right ventricular outflow tract is still a challenge.

We report a technical alternative for pulmonary valve replacement in a dilated and ruptured pulmonic homograft.

\section{Case presentation}

A 31-year-old female patient was hospitalized due to signs of severe right heart failure (NYHA III-IV). The patient had a Shone complex after ROSS procedure and mechanical mitral valve replacement (25 mm Carbomedics) with a history of 5 open-heart surgeries, stenting of recoarctation and pacemaker insertion after total AV-block following ROSS procedure. Actually, 21 years after surgical implantation of a homograft computer tomography revealed a $15 \mathrm{~mm}$ rupture of the calcified pulmonic homograft (originally $22 \mathrm{~mm}$ diameter) with retrosternal and sternal bleeding (Figure 1). To cover the $15 \mathrm{~mm}$ long perforation at the level of the $23.2 \mathrm{~mm}$ annulus (average diameter) in close proximity to a large right ventricular outflow tract and a dilated pulmonary trunk (Figure 2) an alternative strategy for the calcified homograft had to be developed to prevent high-risk open-heart-surgery. After discussion in the interdisciplinary heart team considering all risk factor a tailored interventional strategy for the ruptured homograft and large right ventricular outflow tract and pulmonary trunk was developed. Patient's informed consent was 

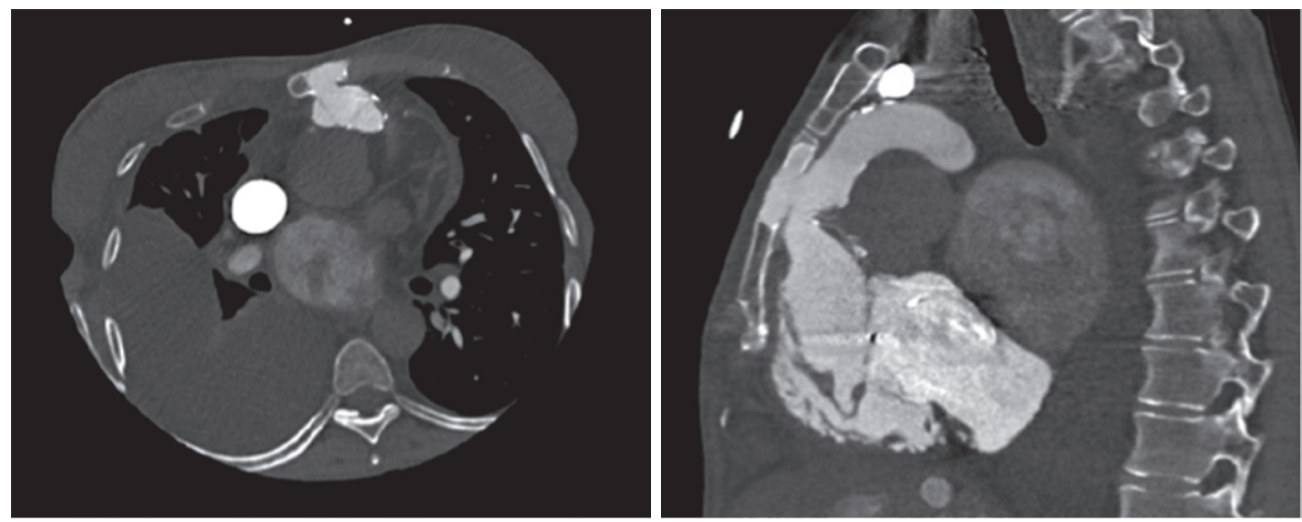

Figure 1 Axial and sagittal MRI images showing a retrosternal and sternal bleeding caused by a spontaneously homograft perforation with a diameter of $12 \mathrm{~mm} \times 15 \mathrm{~mm}$.
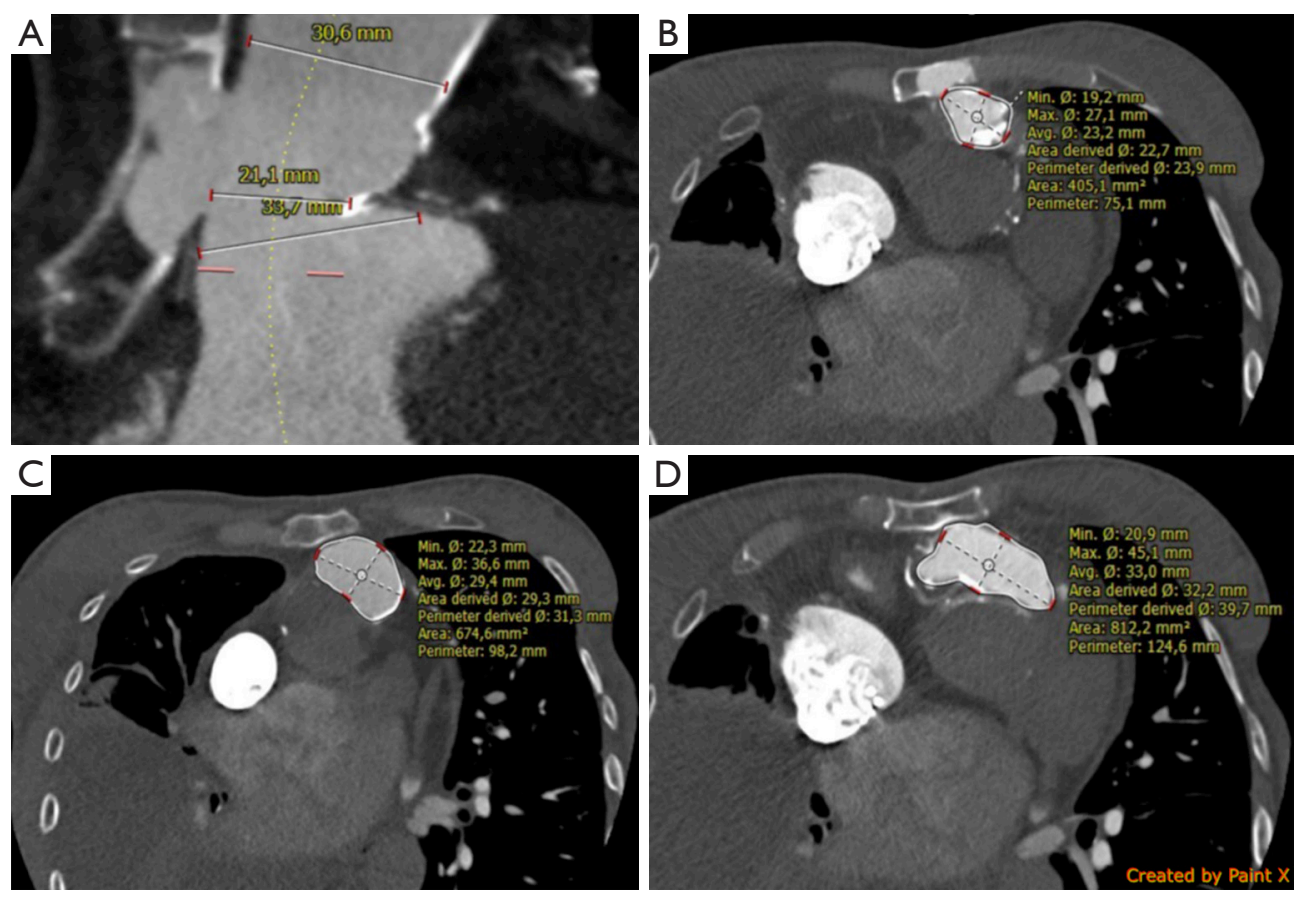

Figure 2 Measurements of the right ventricular outflow tract: (A) sagittal oblique CT reconstruction of the right ventricular outflow tract; (B) cross sectional CT reconstruction of the right ventricular outflow tract close to the homograft perforation; (C) cross sectional CT reconstruction through the valve annulus; (D) cross sectional CT reconstruction of the pulmonary trunk close to the homograft perforation.

obtained.

Venous and arterial accesses were established at the right femoral vein and artery. Right heart catheterization showed no signs of pre-capillary pulmonary hypertension, however volume load of the right ventricle was elevated with the severe regurgitation of the homograft and moderate tricuspid regurgitation in periprocedural transesophageal echocardiography. Via the $6 \mathrm{Fr}$ sheath in the femoral artery, a 6 Fr EBU guiding catheter (Medtronic, Minneapolis, Minnesota, USA) was placed followed by wiring of the left anterior descending and circumflex artery with two BMW wires (Abbott Vascular, Santa Clara, USA) to protect both arteries during the procedure.

In order to cover the $15 \mathrm{~mm}$ perforation of the calcified 

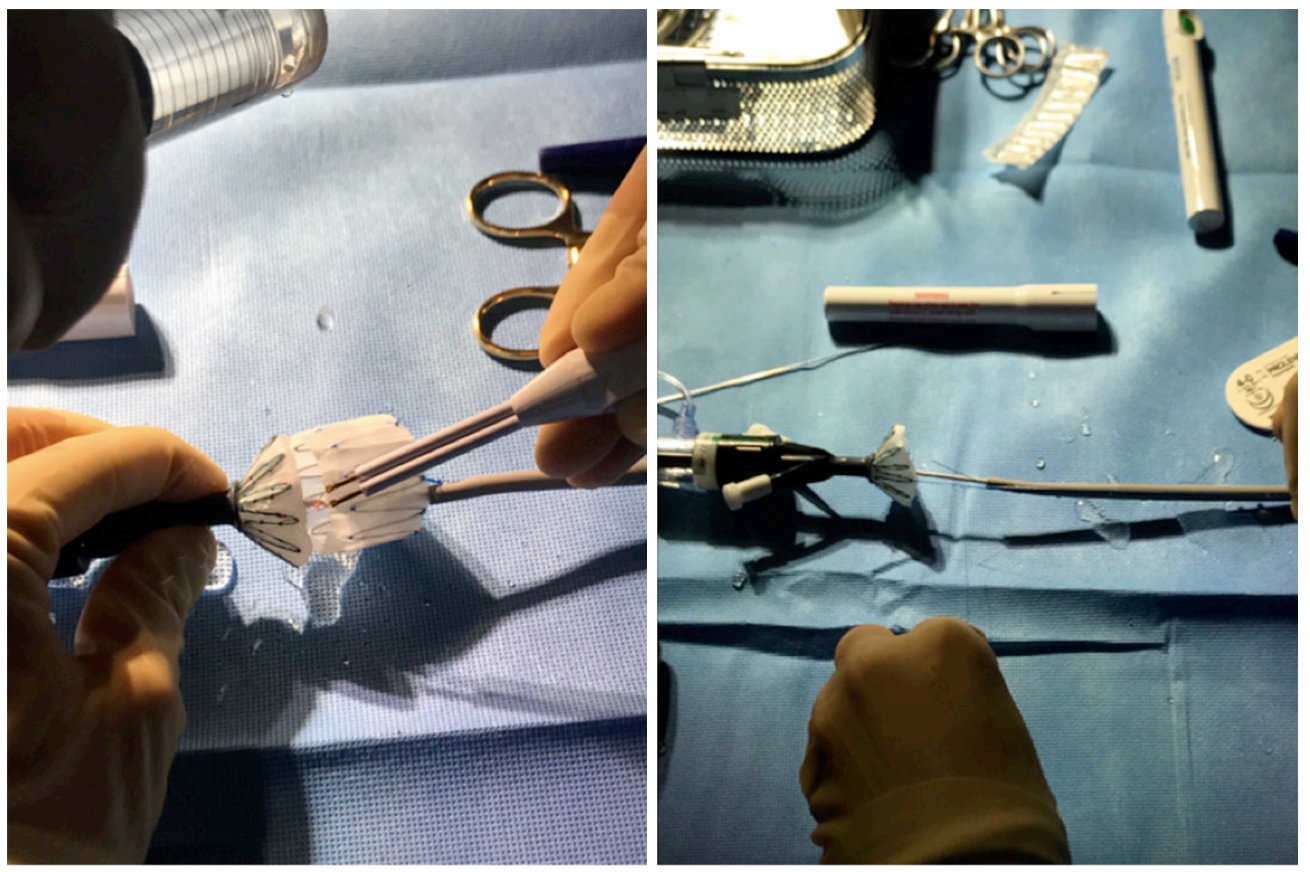

Figure 3 Shortening of the $77 \mathrm{~mm}$ stent-graft (3 stents) to a length of $52 \mathrm{~mm}$ by cutting of the distal stent and fixation of the residual stentgraft using two 5/0 monofilament sutures that were attached to stainless steel trigger wire controlling the distal fixation.

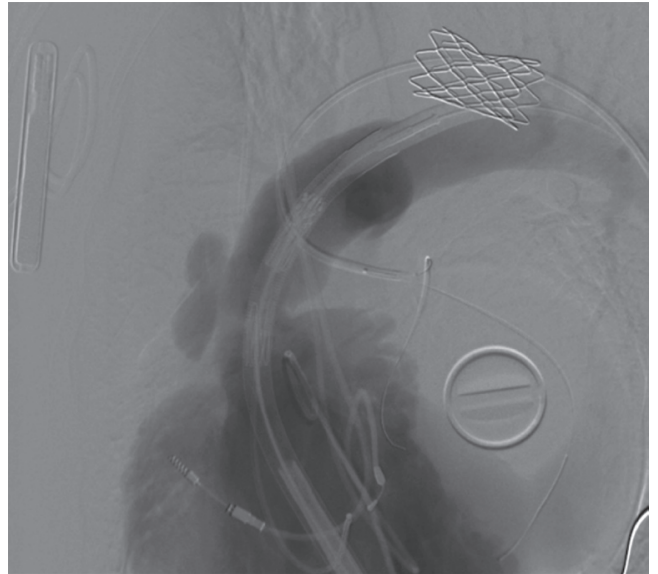

Figure 4 Digital subtraction angiography of the ruptured pulmonic homograft for exact positioning of the shortened Zenith TBE.

homograft and provide a safe anchoring for the balloonexpandable transcatheter valve placement of a self-expanding stentgraft in the enlarged right-ventricular outflow tract was performed. As no stent-grafts with adequate diameter and length were available $34 \mathrm{~mm}$ wide and $77 \mathrm{~mm}$ long Zenith TBE (Cook Medical Europe, Bjaeverskov, Denmark) was surgically modified. The stent-graft was partially deployed through the Captor-valve out of the peel-away sheath. The fabric was shortened using electrocautery between the midand the distal stent, thereby shortening the stent-graft to a length of $52 \mathrm{~mm}$. The distal fixation of the stent-graft was replaced using two 5/0 monofilament sutures that were attached to stainless steel trigger wire controlling the distal fixation (Figure 3).

The surgeon-modified stent-graft was then reloaded and prepared for insertion according to instruction for use. A double curved extra-stiff Lunderquist wire (Cook Medical Europe, Bjaeverskov, Denmark) was placed in the left lower pulmonary artery and the surgeon-modified stent-graft was placed under angiographic control to cover the $15 \mathrm{~mm}$ long homograft perforation (Figure 4). After the placement of the stent-graft a $26 \mathrm{~mm}$ Edward Sapien 3 valve was inserted via a $16 \mathrm{Fr}$ e-sheat into the Zenith TBE. Sapien S3 valve was placed as connecting stent element in between the two stent parts of the Zenith graft (Figure 5) on the level of the former annulus. Both stents were implanted under rapid ventricular pacing. Angiographic and hemodynamic controls revealed complete coverage of the perforation and good valve function (Figure 6).

The patient could be dismissed 3 days after the implantation of the valve without signs of residual right 

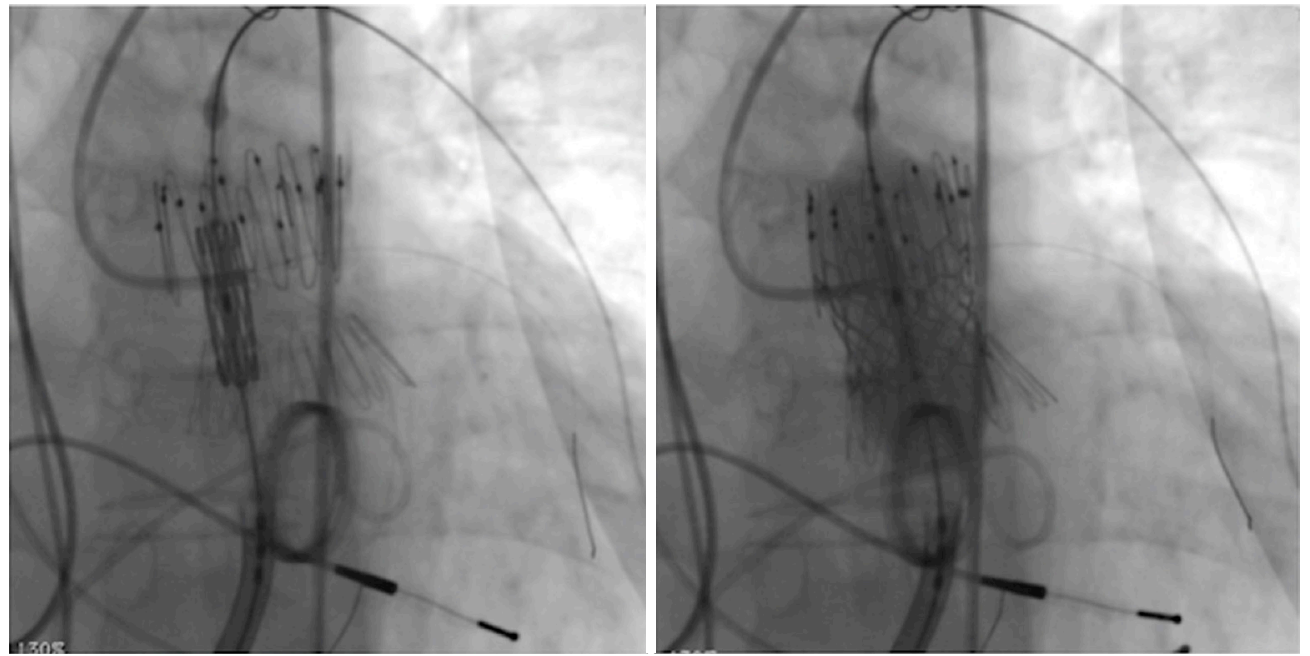

Figure 5 Positioning of the Sapien valve in between both stent-parts of the tailored Zenith graft for better stability.

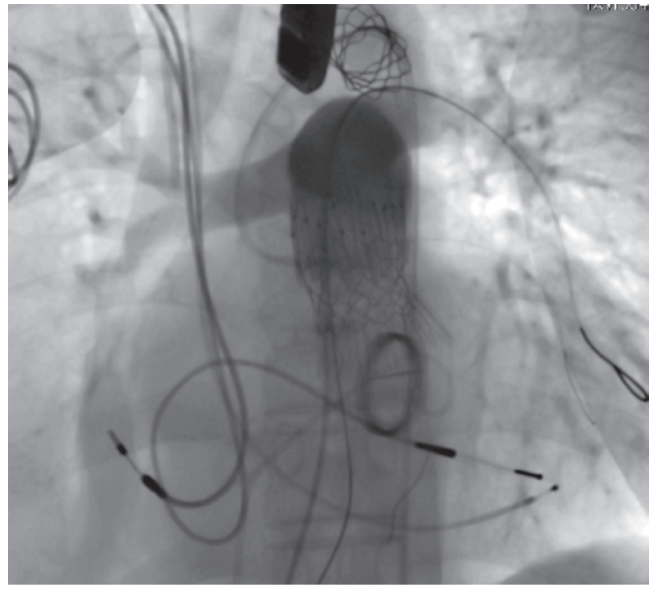

Figure 6 Complete coverage of the homograft perforation and regular function of the Edwards Sapiens S3 valve.

heart failure. Nine-month follow-up showed good results with improved anamnestic exercise capacity, regular valve function, full coverage of the perforation and without any symptoms. CT showed regular form and position of the self-expandable Zenith graft in composition with the Edwards Sapien S3 valve (Figure 7).

\section{Conclusions}

The patient illustrates the need of further technical development for endovascular treatment of large right ventricular outflow tracts and the power of a multidisciplinary team approach in order to get best possible results in adult CHD patients. By using the tailored Zenith endovascular graft, which was developed for treatment of aneurysms, dissections or contained ruptures in the descending thoracic aorta, the $15 \mathrm{~mm}$ long homograft perforation on the level of the annulus in close proximity to the enlarged outflow tract and pulmonary trunk could be successfully covered. In this individual case Zenith TBE offers a valuable alternative. The proximal self-expanding stent fitted exactly in the enlarged right ventricular outflow tract and the distal stent in the large pulmonary trunk without further elongation of the perforation. The complete woven polyester coverage of the graft opens the opportunity to cover the long perforation of the calcified homograft despite the directly adjoining enlarged anatomies of outflow tract and pulmonary trunk. For further stabilization of the flexible connecting part between both stent-parts of the Zenith graft $26 \mathrm{~mm}$ Sapien S3 stent was implanted in between both stent parts on the level of the former valve annulus. In this anatomy off-label use of the self-expanding Zenith endovascular graft was favoured towards certified balloon expandable covered stents because of the expected full coverage of the perforation, balanced stent force before and after the fractured homograft with optimal graft to outflow tract apposition in this enlarged anatomy. 

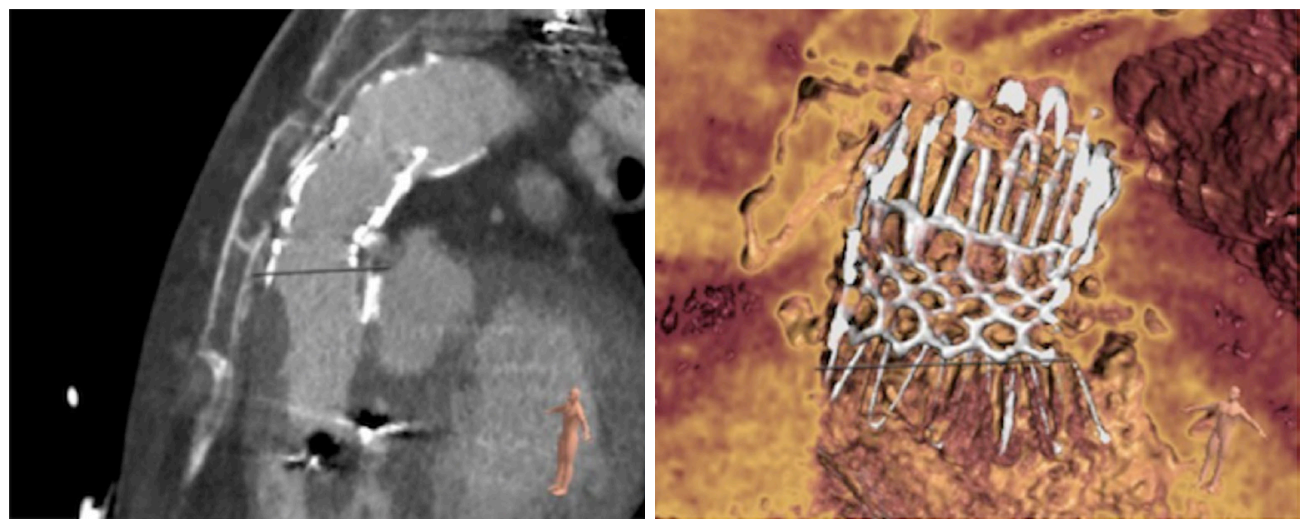

Figure 7 CT images after post-processing using 3 mensio showed regular form and position of the composition of tailored Zenith TBE graft and Edwards Sapien S3 valve nine month after implantation.

\section{Acknowledgements}

None.

\section{Footnote}

Conflicts of Interest: The authors have no conflicts of interest to declare.

Informed Consent: Written informed consent was obtained from the patient for publication of this manuscript and any accompanying images.

\section{References}

1. McElhinney DB, Hennesen JT. The Melody(R) valve and Ensemble(R) delivery system for transcatheter pulmonary valve replacement. Ann N Y Acad Sci 2013;1291:77-85.

Cite this article as: Müller GC, Sinning C, Zengin-Sahm E, Stark V, Mir TS, Rickers C, Kozlik-Feldmann R, Kölbel T, Schäfer U. "Tailored" endovascular pulmonary valve and root replacement for rupture of a dilated homograft. Cardiovasc Diagn Ther 2018;8(6):820-824. doi: 10.21037/cdt.2018.11.06
2. Bonhoeffer P, Boudjemline $Y$, Saliba Z, et al. Percutaneous replacement of pulmonary valve in a right-ventricle to pulmonary-artery prosthetic conduit with valve dysfunction. Lancet 2000;356:1403-5.

3. Morray BH, McElhinney DB, Boudjemline Y, et al. Multicenter Experience Evaluating Transcatheter Pulmonary Valve Replacement in Bovine Jugular Vein (Contegra) Right Ventricle to Pulmonary Artery Conduits. Circ Cardiovasc Interv 2017;10(6).

4. Lurz P, Nordmeyer J, Giardini A, et al. Early versus late functional outcome after successful percutaneous pulmonary valve implantation: are the acute effects of altered right ventricular loading all we can expect? J Am Coll Cardiol 2011;57:724-31.

5. O'Byrne ML, Gillespie MJ. Will catheter interventions replace surgery for valve abnormalities? Curr Opin Cardiol 2014;29:83-90. 